\title{
Surgery for lung cancer
}

\author{
S W Fountain
}

Although the profile of lung cancer has been raised recently, specifically ${ }^{1}$ and in the context of the general re-organisation of cancer services, ${ }^{2}$ concerns remain about the process of management ${ }^{3}$ and the delays in treatment which result. ${ }^{4}$ There is virtually uniform acceptance of the fact that, for patients with non-small cell lung cancer (NSCLC) at least, the best chance of cure is surgery ${ }^{5}$ and that successful surgery depends on diagnosis at an early stage in the disease process. ${ }^{6}$ Some evidence exists to suggest that, in Europe ${ }^{7}$ and the United States, ${ }^{8}$ almost $30 \%$ of patients with NSCLC undergo surgery. Although isolated reports from the UK quote operability rates of $20 \%,{ }^{9}$ the overall resection rate is essentially static ${ }^{10}$ at $10 \%$ or less of the total number of new cases reported each year. ${ }^{11}$ Case selection and long term survival are, however, very similar in this and other countries. ${ }^{12}$ While it is always dangerous to compare figures compiled in different ways, there is an implication that greater numbers could be cured in the UK if more had timely access to surgery.

If the assumption that there is room for improvement can be agreed, the issue becomes that of identifying the areas where it can be achieved. Screening the at risk population has not been shown to be effective in improving survival $^{13}$ and so it is in the patient's journey from the development of symptoms to the institution of treatment where the improvement needs to take place. Most studies are conducted by hospital specialists dealing with identifiable and easily measurable data points. These techniques allow for accurate acquisition of information from which firm conclusions can be drawn, but tell us little about the patient's experience before reaching the hospital environment. In a recent study of the patients' perspective ${ }^{14} 29 \%$ underestimated the significance of their own symptoms and delayed seeking medical advice for one to four months; $15 \%$ waited for over a month for chest radiography after consulting their GPs. Once patients are "in the system" further delays may occur due to poor organisation and lack of focus in the service provided. ${ }^{15}$ The British Thoracic Society (BTS) has recently addressed this problem in more detail than the Standing Medical Advisory Committee report ${ }^{1}$ and the new BTS guidelines are published with this issue of Thorax. ${ }^{16}$ This document makes very specific recommendations about the timing and nature of the investigations which should be performed in patients with suspected lung cancer. In cases thought to be suitable for surgery, a maximum of eight weeks should elapse between first consultation with a respiratory physician and performance of the operation required. While this should serve to set future standards for practitioners and health authorities, also reported in this issue of Thorax are what might be described as the preliminary results of a focused lung cancer service in operation. ${ }^{17}$ In this study a startlingly high resection rate of $25 \%$ was achieved in patients with NSCLC. The authors ascribe their success to quick access, high rates of histological confirmation, routine computed tomographic (CT) scans, and surgical review for all patients, but they also state that at the beginning of the exercise "all GPs in three health authorities were informed of the change in practice ...", and it is likely that this raising of awareness had some effect. Their case mix was similar to that of other series, but it remains to be seen what effect accelerating the diagnostic process and routine surgical review will have on operability in large numbers. It may be that operable patients are, in fact, a select group with slow growing tumours and that those with aggressive disease pass too rapidly through the window of opportunity to be diagnosed in time for cure, as is thought to be the case in some other cancers. ${ }^{18}$ Cynics will also doubt whether this experience, gained in a discrete predominantly rural geographical area, can be reproduced in large densely populated industrial centres, but their results constitute a challenge which no one engaged in the management of lung cancer should ignore.

Publicity campaigns, such as that of Macmillan Cancer Relief, ${ }^{19}$ should take patients to their general practitioners earlier. Adherence to the BTS guidelines should drive them through the system more quickly and Health Authorities, mindful of the emphasis on standards contained in the government's White Paper, ${ }^{20}$ should ensure that these guidelines are followed. The hypothesis that speedy and aggressive investigation will lead to an increase in successful surgical resection can then be tested. The stakes are high: an increase in operability from $10 \%$ to $20 \%$ would mean an additional 3000 patients having surgery each year. Of these, $45 \%$ - that is, 1350 - could expect to be cured by surgery alone.

Harefield Hospital,

Harefield,

Middlesex UB9 67H,

$U K$

1 Standing Medical Advisory Committee. Management of lung cancer: current clinical practices. London: Department of Health, 1994.

2 Expert Advisory Group on Cancer to the Chief Medical Officers of England and Wales. A policy framework for commissioning cancer services. London: Department of Health, 1995.

3 Muers MF, Haward RA. Management of lung cancer. Thorax 1996;51:55760 .

4 George PJM. Delays in the management of lung cancer. Thorax 1997;52:107-8.

5 Pearson FG. Current status of surgical resection of lung cancer. Chest 1994; 106:337-9s.

6 Mountain CF. Revisions in the international system for staging lung cancer. Chest 1997;111:1710-7.

7 Berrino F, Saut M, Verdecchia A, et al, eds. Survival of cancer patients in Europe. The Eurocare study. Geneva: IARC Scientific Publications No. 132, 1995 .

8 Humphrey EW, Smart CR, Winchester DP, et al. National survey of the pattern of care for carcinoma of the lung. $\mathcal{F}$ Thoracic Cardiovasc Surg 1990;100: 837-43.

9 Ferguson RJ, Gregor A, Dodds R, et al. Management of lung cancer in South East Scotland. Thorax 1996;51:569-74.

10 Society of Cardiothoracic Surgeons of Great Britain and Ireland. UK ThoSociety of Cardiothoracic Surg.
racic Surgical Register, 1995.

11 Cancer Research Campaign. Lung cancer and smoking. UK Factsheet 11. London: Cancer Research Campaign, 1996.

12 Al-Kattan K, Sepsas E, Townsend ER, et al. Factors affecting long term survival following resection for lung cancer. Thorax 1996;51:1266-9.

13 Melamed MR, Flehinger BJ, Zaman MB, et al. Screening for early lung cancer: results of the Memorial Sloane-Kettering Study in New York. Chest 1984;86:44-53.

14 Krishnasamy M, Wilkie E. Lung cancer: patients', families' and professionals' perceptions of health care need. A national needs assessment study. Preliminary report to Macmillan Cancer Relief, 1997.

15 Pickles H, Rudolf M. Lung cancer: review of local services. Thorax 1996;51(Suppl 3):57.

16 British Thoracic Society. BTS recommendations to respiratory physicians for organising the care of patients with lung cancer. Thorax 1998;53(Suppl 1): $\mathrm{S} 1-8$.

17 Laroche C, Wells F, Coulden R, et al. Improving surgical resection rate in lung cancer. Thorax 1998;53:445-9.

18 Schmidt JG. Delays in diagnosing oesophagogastric cancer. BMf 1997;315: 426-7.

19 Breathing Easier; A guide to the treatment and care of lung cancer. London: Macmillan Cancer Relief, 1997.

20 The new NHS. London: Department of Health, 1997. 